\title{
Stable carbon isotope ratios of ambient secondary organic aerosols in Toronto
}

\author{
M. Saccon ${ }^{1}$, A. Kornilova ${ }^{1}$, L. Huang ${ }^{2}$, S. Moukhtar ${ }^{1}$, and J. Rudolph ${ }^{1}$ \\ ${ }^{1}$ Centre for Atmospheric Chemistry, York University, 4700 Keele St., Toronto, ON, M3J 1P3, Canada \\ ${ }^{2}$ Climate Research Division, Atmospheric Science and Technology Directorate, Environment Canada, 4905 Dufferin St., \\ Toronto, ON, M3H 5T4, Canada
}

Correspondence to: J. Rudolph (rudolphj@yorku.ca)

Received: 16 March 2015 - Published in Atmos. Chem. Phys. Discuss.: 9 June 2015

Revised: 10 September 2015 - Accepted: 14 September 2015 - Published: 29 September 2015

\begin{abstract}
A method to quantify concentrations and stable carbon isotope ratios of secondary organic aerosols has been applied to study atmospheric nitrophenols in Toronto, Canada. The sampling of five nitrophenols, all with substantial secondary formation from the photooxidation of aromatic volatile organic compounds (VOCs), was conducted in the gas phase and particulate matter (PM) together and in PM alone. Their concentrations in the atmosphere are in the low $\mathrm{ng} \mathrm{m}^{-3}$ range and, consequently, a large volume of air $\left(>1000 \mathrm{~m}^{3}\right)$ is needed to analyze samples for stable carbon isotope ratios, resulting in sampling periods of typically $24 \mathrm{~h}$. While this extended sampling period increases the representativeness of average values, it at the same time reduces possibilities to identify meteorological conditions or atmospheric pollution levels determining nitrophenol concentrations and isotope ratios.

Average measured carbon isotope ratios of the different nitrophenols are between -34 and $-33 \%$, which is well within the range predicted by mass balance. However, the observed carbon isotope ratios cover a range of nearly $9 \%$ and approximately $20 \%$ of the isotope ratios of the products have isotope ratios lower than predicted from the kinetic isotope effect of the first step of the reaction mechanism and the isotope ratio of the precursor. This can be explained by isotope fractionation during reaction steps following the initial reaction of the precursor VOCs with the $\mathrm{OH}$ radical.

Limited evidence for local production of nitrophenols is observed since sampling was done in the Toronto area, an urban center with significant anthropogenic emission sources. Strong evidence for significant local formation of nitrophenols is only found for samples collected in summer. On aver-
\end{abstract}

age, the difference in carbon isotope ratios between nitrophenols in the particle phase and in the gas phase is insignificant, but for a limited number of observations in summer, a substantial difference is observed. This indicates that at high $\mathrm{OH}$ radical concentrations, photochemical formation or removal of nitrophenols can be faster than exchange between the two phases.

The dependence between the concentrations and isotope ratios of the nitrophenols and meteorological conditions as well as pollution levels $\left(\mathrm{NO}_{2}, \mathrm{O}_{3}, \mathrm{SO}_{2}\right.$ and $\left.\mathrm{CO}\right)$ demonstrate that the influence of precursor concentrations on nitrophenol concentrations is far more important than the extent of photochemical processing. While it cannot be excluded that primary emissions contribute to the observed levels of nitrophenols, overall the available evidence demonstrates that secondary formation is the dominant source for atmospheric nitrophenols in Toronto.

\section{Introduction}

Volatile organic compounds (VOCs) are emitted into the atmosphere by both anthropogenic and biogenic sources. Once emitted, the VOCs undergo both physical and chemical processes, such as dilution and chemical reactions. Reactions in the atmosphere are mainly oxidation reactions with $\mathrm{OH}$, ozone or chlorine radicals. These oxidation reactions produce products which are typically heavier and have lower vapor pressures than the precursor. Many of the products are considered to be semi-volatile organic compounds (SVOCs), which have properties that allow them to exist both in the 
gas phase and in particulate matter (PM) and compose secondary organic aerosols, making up a substantial portion of aerosols in the troposphere. Nitrophenols, the target compounds of this paper, are SVOCs that are produced by processes in the atmosphere from aromatic VOCs such as benzene, toluene and $\mathrm{m}$-xylene, according to the reaction scheme in Fig. 1 (Forstner et al., 1997; Atkinson, 2000; Jang and Kamens, 2001; Hamilton et al., 2005; Sato et al., 2007). The nitrophenol formation pathway from toluene and m-xylene is proposed to be similar. Once emitted, the aromatic VOCs can undergo photooxidation with the $\mathrm{OH}$ radical to produce a (di)methyl hydroxycyclohexadienyl radical, which can then form a (di)methyl phenol (Forstner et al., 1997). These intermediates can then react with $\mathrm{OH}$ and $\mathrm{NO}_{2}$ to produce (di)methyl nitrophenols.

4-Nitrophenol has several proposed formation pathways which include pathways in both the gas phase and the aqueous phase. Atkinson et al. (1992) proposed that benzene undergoes photooxidation to produce a phenoxy radical with subsequent reaction with $\mathrm{NO}_{2}$. Alternatively, Bolzacchini et al. (2001) suggested the addition of $\mathrm{NO}_{3}$ to the $\mathrm{OH}$ carbon of phenol, followed by the addition of $\mathrm{NO}_{2}$ to the para carbon and final loss of $\mathrm{HNO}_{3}$, forming 4-nitrophenol. Irei et al. (2015) found 4-nitrophenol to be a reaction product from the gas phase photooxidation of toluene.

It has been proposed that the aqueous phase production of nitrophenols could occur from the reaction of cresols with $\mathrm{NO}_{3}$ (Herrmann et al., 1995). Aqueous phase formation of 4nitrophenol has also been proposed by Harrison et al. (2005), suggesting that once phenol is produced from the reaction of benzene and the $\mathrm{OH}$ radical, it partitions into the aqueous phase and reacts with $\mathrm{NO}_{3}$ to form 4-nitrophenol, which then partitions favorably into the gas phase. Based on model calculations, the aqueous formation processes can have a substantial contribution to the total formation rate at high liquid water content, such as in clouds, but this process contributes less than $2 \%$ to nitrophenol formation at low liquid water contents (Harrison et al., 2005).

Nitrophenols have been found in trace amounts as primary emissions, such as gasoline-fueled automobile exhaust (Tremp et al., 1993). In a very recent study, Inomata et al. (2015) reported that emission factors for 4-nitrophenol in PM from gasoline fueled engines are below the quantification limits of $6 \times 10^{-3} \mu \mathrm{g} \mathrm{km}^{-1}$, whereas for diesel engines emission factors ranged from 0.23 to $29.5 \mu \mathrm{g} \mathrm{km}^{-1}$ for 4-nitrophenol in PM. The reported values for 3-methyl-4nitrophenol and 2-methyl-4-nitrophenol are in the range of 0.32 to $11.4 \mu \mathrm{g} \mathrm{km}^{-1}$ for diesel engines and were below the quantification limits for gasoline engines. 4-Nitrophenol has also been found in the gas phase of diesel engine exhaust at highly variable levels (Inomata et al., 2013) corresponding to emissions factors ranging from effectively 0 to hundreds of $\mu \mathrm{g} \mathrm{km}^{-1}$.

Considering the many possible sources of atmospheric nitrophenols, it can be difficult to identify the most important sources using only concentration measurements. Stable carbon isotope ratio measurements have been useful tools in atmospheric chemistry (Gensch et al., 2014). The ratio of the ${ }^{13} \mathrm{C}$ isotope, which has a natural abundance of approximately $1.1 \%$, and the ${ }^{12} \mathrm{C}$ isotope is compared to a standard, the Vienna Pee Dee Belemnite (V-PDB) with a value of 0.0112372 (Craig, 1957), as shown in Eq. (1). This relative difference in per mill notation is referred to as the delta value $\left(\delta^{13} \mathrm{C}\right)$. Stable carbon isotope ratio measurements in combination with concentration measurements have been proposed to be used to gain insight into the formation and processing of secondary organic aerosols in the atmosphere (Goldstein and Shaw, 2003; Rudolph, 2007; Gensch et al., 2014). Although still a developing field, especially in atmospheric chemistry, stable carbon isotope ratio measurements have been used to measure a wide range of compounds to gain information on sources, chemical processes and transport in the atmosphere. Nitrophenols were chosen as the target compounds in this study for three reasons. The first reason is that nitrophenols are formed from one reaction pathway and are specific to the aromatic $\mathrm{VOC}+\mathrm{OH}$ reaction (Forstner et al., 1997). This is important so that the nitrophenols can be traced back to the precursor, which has a measured and known isotope ratio at the source (Rudolph et al., 2002). Secondly, the target compounds should be ring retaining products so that the possibility of being formed from other precursors decreases compared to ring fragmentation products. Lastly, and most importantly, it has been shown that one of the methyl nitrophenols, 2-methyl-4-nitrophenol, has an isotope ratio that is within $\pm 1.33 \%$ of the isotope ratio of the sum of all reaction products for the reaction of toluene (between 10 and $27 \%$ reacted) with the $\mathrm{OH}$ radical, allowing for a first-order prediction of the dependence between isotope ratios of reaction products and photochemical precursor processing in the atmosphere from mass balance calculations (Irei et al., 2015). Measurements of nitrophenol concentrations and their isotope ratios in a mixed residential and industrial area are reported and discussed in this paper.

$\delta^{13} \mathrm{C}=\frac{\left({ }^{13} \mathrm{C} /{ }^{12} \mathrm{C}\right)_{\text {sample }}-\left({ }^{13} \mathrm{C} /{ }^{12} \mathrm{C}\right)_{\mathrm{V}-\mathrm{PDB}}}{\left({ }^{13} \mathrm{C} /{ }^{12} \mathrm{C}\right)_{\mathrm{V}-\mathrm{PDB}}} \times 1000 \%$

\section{Method}

The method used for filter preparation, sample collection, extraction and analysis has been previously described by Saccon et al. (2013), Moukhtar et al. (2011) and Irei et al. (2013). Samples were collected at York University (Fig. 2) in the outskirts of Toronto, Canada, using high volume air samplers (Fig. 2). Figure 2 also shows the location of two monitoring stations of the Ontario Ministry of the Environment (OME), which provided measurements of ambient concentrations of $\mathrm{NO}_{2}, \mathrm{O}_{3}, \mathrm{CO}, \mathrm{SO}_{2}$ and $\mathrm{PM}$ with a nominal aerodynamic diameter of less than $2.5 \mu \mathrm{m}\left(\mathrm{PM}_{2.5}\right)$. The sampling period was from March 2009 to August 2012. Prebaked 


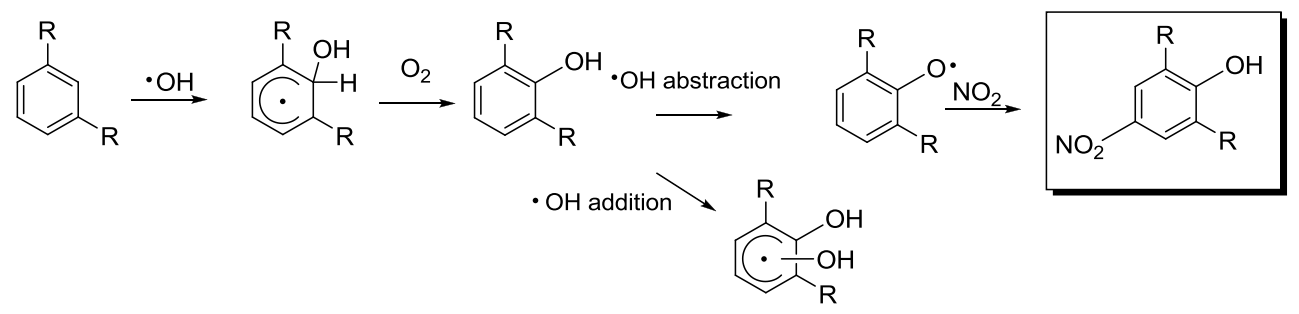

Figure 1. Reaction scheme of proposed mechanism of the gas phase formation pathway of the target compounds from aromatic VOCs. Here, the $R$ represents either a hydrogen atom or a methyl group (adapted from Forstner et al., 1997).

quartz fibre filters were used for PM collection and prebaked quartz fibre filters coated with XAD- $4{ }^{\circledR}$ resin were used for gas phase + PM collection. The sampling times for XAD- $4{ }^{\circledR}$ coated filters were typically $24 \mathrm{~h}$ and from 1 to 3 days for uncoated filters.

Uncoated quartz filters have the possibility of sampling artifacts, including gas phase target compounds. Nitrophenol artifacts could not be ruled out but were found to be limited. The mass of artifacts on a filter is expected to be proportional to sampling time. For the target compounds analyzed, an average percent difference of approximately $6.5 \%$ was observed between three samples collected for 1 day each and a sample collected continuously for 3 days. Saccon et al. (2013) showed that partitioning results from denuder sampling, which is designed to limit artifacts from the separation of the gas phase from the PM phase, are consistent with results from conventional filter sampling, such that the majority of nitrophenols are found in the gas phase. From denuder sampling experiments it is estimated that the gas phase component of each of the target compounds, apart from 4-methyl2-nitrophenol, is about 10 to $30 \%$ higher than what is found from high volume filter samples. This difference is consistent with the sampling efficiency of XAD- $4{ }^{\circledR}$ coated filters (Saccon et al., 2013).

Filters, prior to extraction, were stored in a freezer. After being spiked with internal standards, filters were extracted with acetonitrile, underwent an HPLC and solid phase extraction cleanup step and were analyzed. An HP 5890 GC coupled to an HP 5972 MS was used for concentration measurements and an HP 6890 GC coupled to a Micromass Isoprime IRMS was used for isotope ratio measurements. All samples were derivatized with bis(trimethylsilyl)trifluoroacetamide prior to analysis. A summary of performance characteristics is shown in Table 1 . Only samples containing more than $3 \mathrm{ng}$ of carbon for at least one of the target compound per $3 \mu \mathrm{L}$ injection were used for quantifying stable carbon isotope ratios.
Table 1. Summary of performance characteristics of the sampling, extraction and analysis method of nitrophenols in PM and in the gas phase + PM (Saccon et al., 2013).

\begin{tabular}{ll}
\hline XAD- $4^{\circledR}$ collection efficiency & $84 \%$ \\
\hline Detection limit & $0.002 \mathrm{ng} \mathrm{m}^{-3}$ \\
GC-MS calibration $R^{2}$ & 0.99 \\
GC-IRMS calibration $R^{2}$ & 0.99 \\
Precision of $\delta^{13} \mathrm{C}$ measurements & $0.3 \%$ \\
Overall uncertainty of $\delta^{13} \mathrm{C}$ measurements & $0.5 \% \circ$ \\
\hline
\end{tabular}

\section{Results and discussion}

\subsection{Overview of measured carbon isotope ratios}

An overview of the measured isotope ratios of nitrophenols is given in Table 2. The nitrophenols chosen as the target compounds for this study were 4-nitrophenol, 4methyl-2-nitrophenol, 3-methyl-4-nitrophenol, 2-methyl-4nitrophenol and 2,6-dimethyl-4-nitrophenol. Since only sample extracts with concentrations of at least $1 \mathrm{ng} \mathrm{LL}^{-1}$ of carbon for a target compound were suitable for isotope ratio measurement, only a subset of the samples collected was analyzed for $\delta^{13} \mathrm{C}$ of the target nitrophenols. This reduced the number of samples with low nitrophenol concentrations and therefore could result in subsets of $\delta^{13} \mathrm{C}$ data biased towards samples with higher nitrophenol concentrations. For the most abundant target compounds, 4-nitrophenol and 2-methyl-4nitrophenol, 85 and $98 \%$, respectively, of the 102 samples (47 PM and 55 gas + PM) could be analyzed for isotope ratios. For the lower in abundance compounds, 4-methyl2-nitrophenol, 3-methyl-4-nitrophenol and 2,6-dimethyl-4nitrophenol, only 17,47 and $22 \%$, respectively, of the samples were analyzed for carbon isotope ratios. As can be seen from Fig. 3, the variability of the carbon isotope ratio substantially exceeds any systematic dependence between concentration and $\delta^{13} \mathrm{C}$.

The range of $\delta^{13} \mathrm{C}$ values covered by the individual target compounds is between 4 and nearly $9 \%$ and $50 \%$ of the $\delta^{13} \mathrm{C}$ values differ by more than $1 \%$ from the average (Fig. 4). The measurement precision is $0.3 \%$ and the re- 


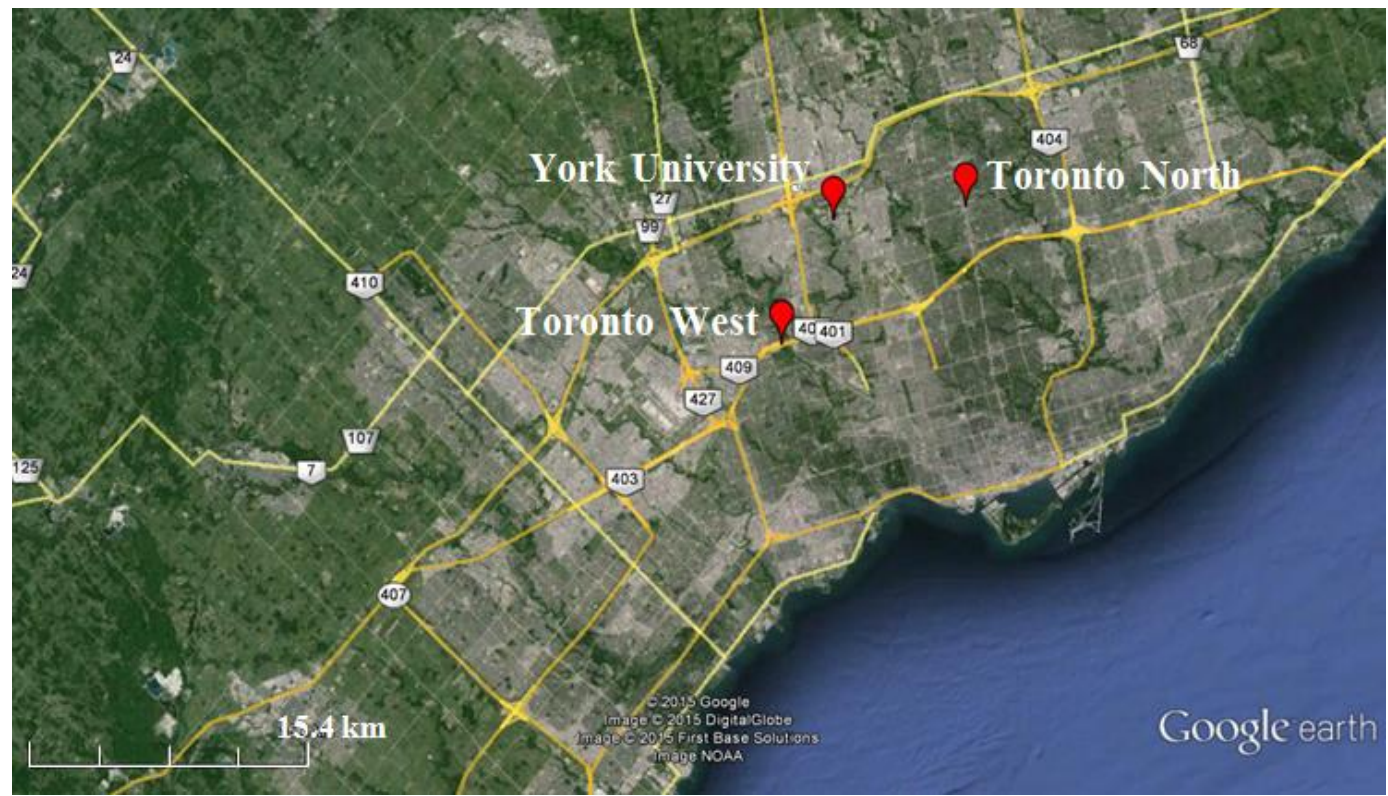

Figure 2. Map showing the sampling site (York University) as well as the Ontario Ministry of Environment (OME) sites (Toronto West and Toronto North) that collected pollutant data. The map was produced using Google Earth Pro, $2015{ }^{\circledR}$ Google, $2015{ }^{{ }^{\circ}}$ DigitalGlobe, 2015 First ${ }^{(} \mathrm{B}$ Base Solutions and NOAA (August, 2009).

Table 2. Summary of ambient isotope ratio measurements of nitrophenols.

\begin{tabular}{llrrrrrrr}
\hline Target compound & Abbreviation & \multicolumn{6}{c}{ Carbon isotope ratio (\%o) } \\
\cline { 3 - 8 } & & Average & Error of the mean & Median & Max & Min & 25th percentile & 75th percentile \\
\hline 4-Nitrophenol & 4-NP & -33.5 & 0.2 & -33.6 & -30.4 & -36.4 & -34.5 & -32.4 \\
4-Methyl-2-nitrophenol & 4-me-2-NP & -33.0 & 0.3 & -33.3 & -30.7 & -34.7 & -33.7 & -32.5 \\
3-Methyl-4-nitrophenol & 3-me-4-NP & -33.1 & 0.3 & -32.9 & -28.4 & -36.2 & -34.2 & -32.2 \\
2-Methyl-4-nitrophenol & 2-me-4-NP & -33.0 & 0.2 & -33.1 & -28.4 & -36.0 & -34.0 & -31.7 \\
2,6-Dimethyl-4-nitrophenol & 2,6-dime-4-NP & -33.6 & 0.4 & -33.6 & -29.4 & -37.0 & -34.9 & -32.2 \\
\hline
\end{tabular}

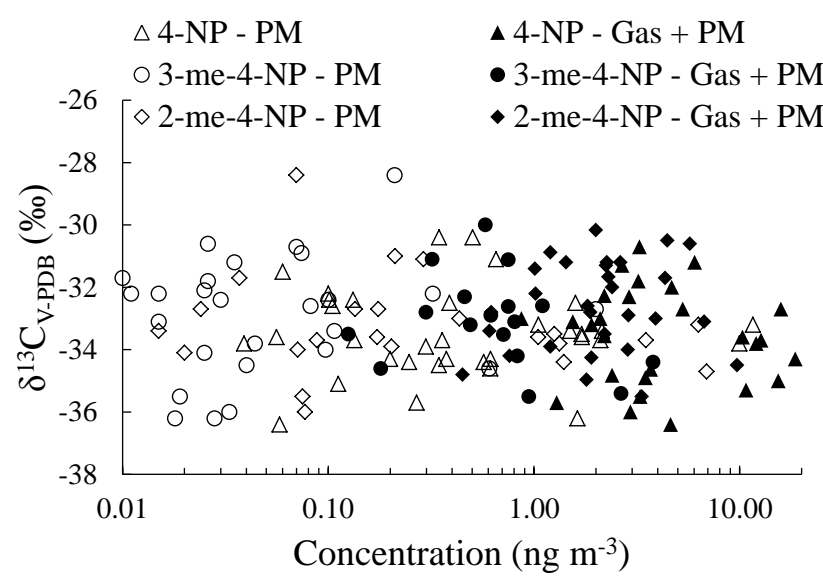

Figure 3. Plot of isotope ratio values as a function of concentration for 4-nitrophenol, 3-methyl-4-nitrophenol and 2-methyl-4nitrophenol. sulting measurement uncertainty for differences between two observations for the same target substance is $0.4 \%$. Differences exceeding 0.7 and $1.1 \%$ exceed the measurement uncertainty within a 90 and $99 \%$ confidence limit, respectively. Therefore, most of the observed variability of the measurements cannot be explained by measurement uncertainty. The dominant factors creating variability in the isotope ratios of organic compounds in the atmosphere are atmospheric reactions or varying contributions from sources with different isotopic composition (Gensch et al., 2014).

Irei et al. (2015) reported that the main factor determining the carbon isotope ratio of the particulate phase products of toluene oxidation is the kinetic isotope effect (KIE) for the reaction of toluene with the $\mathrm{OH}$ radical and the carbon isotope ratio of the reacting toluene. The KIEs for the reactions of benzene, toluene and m-xylene with the $\mathrm{OH}$ radical have been measured in the laboratory (Anderson et al., 2004) and the carbon isotope ratio of their emissions in the Greater Toronto Area (GTA) have been determined by Rudolph et al. (2002). Using these values, which are summarized in Ta- 
Table 3. Rate constants $\left(k_{\mathrm{OH}}\right)$, carbon KIE for reactions of aromatic hydrocarbons with $\mathrm{OH}$ radicals and isotope ratio of emissions $\left(\delta^{13} \mathrm{C}_{0}\right)$. Also given are carbon isotope ratios of reaction products formed by the reaction of the unprocessed emissions of precursor VOCs $\left(\delta^{13} \mathrm{C}_{i}\right)$.

\begin{tabular}{lrrrr}
\hline & $k_{\mathrm{OH}}^{\mathrm{a}}\left(\mathrm{cm}^{3} \mathrm{molec}^{-1} \mathrm{~s}^{-1}\right)$ & $\mathrm{KIE}^{\mathrm{b}}(\% \circ)$ & $\delta^{13} \mathrm{C}_{0}^{\mathrm{c}}(\% \circ)$ & $\delta^{13} \mathrm{C}_{i}^{\mathrm{d}}(\% o)$ \\
\hline Benzene & $1.39 \times 10^{-12}$ & $7.83 \pm 0.42$ & $-26.9 \pm 1.7$ & $-34.7 \pm 1.8$ \\
Toluene & $5.63 \times 10^{-12}$ & $5.95 \pm 0.28$ & $-27.6 \pm 0.9$ & $-33.5 \pm 0.9$ \\
m-Xylene & $2.31 \times 10^{-11}$ & $4.83 \pm 0.05$ & $-27.4 \pm 0.5$ & $-32.2 \pm 0.5$ \\
\hline${ }^{a} \begin{array}{l}\text { Calvert et al. (2002); }{ }^{\mathrm{b}} \text { Anderson et al. (2004); }{ }^{\mathrm{c}} \text { Rudolph et al. (2002). } \\
\text { calculated from the uncertainties of the emission and of the KIE for reaction with OH radicals. }\end{array}$
\end{tabular}

ble 3, the carbon isotope ratios of nitrophenols formed from unprocessed emissions can be estimated from the isotope ratio of the emissions and the KIE (Table 3). It should be noted that the $\delta^{13} \mathrm{C}$ values for the methyl nitrophenols formed by the gas phase photooxidation of toluene in laboratory experiments are in many cases between 1 and $4 \%$ olighter than predicted by a model based on reaction mechanisms proposed in literature and the assumption that the isotope fractionation between precursor and product is completely determined by the initial reaction step (Irei et al., 2015). Since these laboratory data exhibit substantial scatter, this possible additional fractionation was not considered in the calculation of the carbon isotope ratios for nitrophenols formed from unprocessed emissions. It is assumed that benzene and m-xylene reactions follow the same principle as postulated by Irei et al. (2015) for toluene reactions. As the reaction progresses, the products will be enriched in ${ }^{13} \mathrm{C}$ due to the reaction of the parent VOC as well as that of the reaction product with the $\mathrm{OH}$ radical in the gas phase. Although the KIEs for reactions of nitrophenols have not been measured, they most likely will be normal KIEs, similar to all KIEs measured for reactions of light aromatic VOCs in the gas phase (Anderson et al., 2004).

The overview of the results in Figs. 3 and 4 and Table 2 shows that nearly all measured $\delta^{13} \mathrm{C}$ values of the target compounds are significantly depleted relative to the parent material (Table 3). This is fully consistent with a secondary origin of the target compounds. However, 4-nitrophenol and two methyl nitrophenol isomers have been found in exhaust from diesel-powered vehicles (Inomata et al., 2013, 2015) and the possibility of contributions from direct emissions has to be considered. The average ratios of 4-nitrophenol over $\mathrm{NO}_{x}$ volume mixing ratios calculated from the results reported by Inomata et al. (2013) range from approximately $5 \times 10^{-5}$ for the engine with the highest 4-nitrophenol emissions to $7.5 \times 10^{-8}$ for the engine with the lowest emissions. The average ratio of 4-nitrophenol over $\mathrm{NO}_{x}$ for our measurements is $9.5 \times 10^{-5}$ on a molar basis with an error of the mean of $0.2 \times 10^{-5}$. Although this comparison ignores the existence of $\mathrm{NO}_{2}$ sources other than diesel engines in the GTA, this is nevertheless a factor of approximately 2 higher than the upper end of emission ratios for the measurements reported by Inomata et al. (2015). Still, based on the limited number of diesel engines investigated by Inomata et al. (2013), it cannot be ruled out that direct emissions to some extent contributed to the 4-nitrophenol concentrations we observed.

4-Nitrophenol has also been found to be a product from toluene photooxidation (Irei et al., 2015) but with a yield that is only about $6 \%$ of the yield for 2-methyl-4-nitrophenol. The carbon isotope ratio of 4-nitrophenol formed by the photooxidation of toluene is, within measurement uncertainty, identical to the carbon isotope ratio of the precursor. Since the measured concentrations of 4-nitrophenol are on average a factor of approximately 2.5 higher than those of the most abundant methyl nitrophenol and the observed 4-nitrophenol carbon isotope ratios are on average $6.6 \pm 1.7 \%$ o lower than those of the parent material, a substantial contribution of toluene oxidation to the observed levels of 4-nitrophenol can be ruled out.

For methyl nitrophenols, a measurable contribution from direct emissions is not likely. The emission factors reported by Inomata et al. (2015) for 3-methyl-4-nitrophenol are between a factor of 45 and 500 lower than the average emission factor of 4-nitrophenol reported by Inomata et al. (2013) for the engine with the highest 4-nitrophenol emission factor, while on average our measured 3-methyl-4-nitrophenol concentrations are only a factor of 7 lower than the 4-nitrophenol concentrations. For 2-methyl-4-nitrophenol, the difference is even larger: the emission factors are between a factor of 65 and 625 lower than for 4-nitrophenol, while our measured concentrations differ on average by only a factor of 2.5. Moreover, Inomata et al. (2015) did not report the observation of 4-methyl-2-nitrophenol in PM from diesel engine exhaust although their quantification limit for this isomer was nearly identical to that for 2-methyl-4-nitrophenol and 3-methyl-4-nitrophenol.

There are no measurements of the carbon isotope ratio of emissions for any of the target compounds, but there have been a substantial number of studies of the carbon isotope ratios of emissions for other VOCs (Gensch et al., 2014). The carbon isotope ratios of VOCs emitted from incomplete combustion sources are either close to the isotope ratios of the parent material or heavier, and all reported traffic- or incomplete combustion-related VOC emissions are heavier than $-29 \%$ o. The measured $\delta^{13} \mathrm{C}$ values of the target compounds are, with very few exceptions, substantially lower 

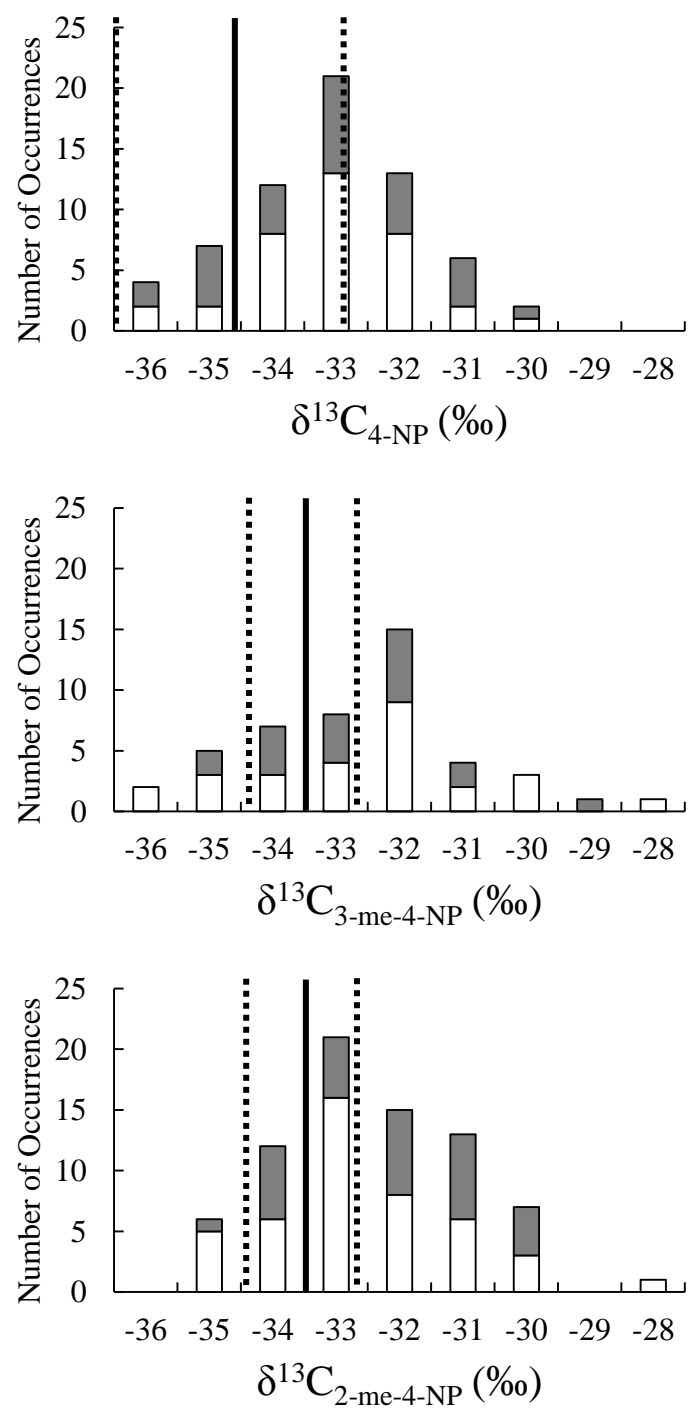

Figure 4. Frequency distribution of ambient stable carbon isotope ratios of 4-nitrophenol, 3-methyl-4-nitrophenol and 2-methyl4-nitrophenol for samples collected in PM alone (white) and in the gas phase and PM together (gray). The solid vertical line in each of the graphs represents the delta value of the nitrophenol formed from the reaction of unprocessed precursor emissions, which is calculated from the carbon isotope ratio of precursor emissions and the KIE for reaction of the precursor with the $\mathrm{OH}$ radical and the dashed vertical lines represent the uncertainty (Table 3 ).

than $-29 \%$, which is consistent with secondary formation from VOC precursors.

It has been postulated that nitrophenols can be formed in clouds via the formation of phenol by the gas phase reaction of benzene with $\mathrm{OH}$ radicals and subsequent absorption of phenol into cloud water. Following the formation of nitrophenols in the liquid phase, the nitrophenols can partition into the gas phase (Harrison et al., 2005). Since the phenol formed by reaction of aromatic VOCs with $\mathrm{OH}$ radicals will be depleted in ${ }^{13} \mathrm{C}$ relative to the parent VOC, such a mechanism would be consistent with the light $\delta^{13} \mathrm{C}$ values observed here. However, the measurements presented here were conducted very close to ground level, at the top of a fourfloor building. Due to the strong vertical gradients of primary pollutants over regions with strong anthropogenic sources (see for example Glaser et al., 2003), only low-level clouds can contribute to the formation of nitrophenols. Harrison et al. (2005) calculated that at a "benchmark" value of a liquid volume fraction of $3 \times 10^{-7}$, corresponding to $0.3 \mathrm{~g} \mathrm{~m}^{-3}$, $58 \%$ of nitrophenol formation is via the liquid phase. This liquid water content is typical for low-level clouds such as stratus or cumulus clouds. For North America, the average coverage with low-level clouds is approximately $18 \%$ (International Satellite Cloud Climatology Project, 2015). Our measurements were made at an altitude much lower than the cloud base of even low-level clouds. Considering all this, overall a significant contribution of cloud processing to the levels of the target compounds we observed can be ruled out.

As predicted by the postulated gas phase formation mechanisms and subsequent reaction with the $\mathrm{OH}$ radical, most of the measured $\delta^{13} \mathrm{C}$ values of 4-nitrophenol are larger than $-34 \%$ (Fig. 4). The lower end of the measured $\delta^{13} \mathrm{C}$ values for 4-nitrophenol is approximately 1 to $2 \%$ lower than $\delta^{13} \mathrm{C}$ values predicted from the $\delta^{13} \mathrm{C}$ values of benzene emissions and the KIE for reaction of benzene with the $\mathrm{OH}$ radical; however, this difference is within the uncertainty of the prediction (Table 3) and the measurement error (Table 1). For two of the reaction products of the photooxidation of toluene, 3-methyl-4-nitrophenol and 2-methyl-4-nitrophenol, the discrepancy between prediction and the lower end of observations is more pronounced. For both compounds, the lower end of the observations is approximately 2 to $3 \%$ o lighter than predicted, a difference that is larger than the uncertainty of the predictions (Table 3). Similarly for 2,6-dimethyl-4nitrophenol, the 25th percentiles are $2.7 \%$ lower than predicted for the reaction of unprocessed VOC emissions. In total, $19 \%$ of all measurements are below the $99 \%$ confidence limit calculated from the combined uncertainty of measurement and $\delta^{13} \mathrm{C}_{i}$. However, a substantial part, if not all, of the uncertainty of $\delta^{13} \mathrm{C}_{i}$ may be systematic. Assuming that the total calculated uncertainty of $\delta^{13} \mathrm{C}_{i}$ is systematic, $12 \%$ of the observations are below the $2 \sigma$ uncertainty of $\delta^{13} \mathrm{C}_{i}$ and $5 \%$ below the $3 \sigma$ limit.

In situations with precursor isotope ratios close to unprocessed emissions, the concentration of secondary compounds will be low. Consequently, it is expected that the lowest nitrophenol carbon isotope ratios will be for samples with low concentrations. In contrast to this expectation there is no systematic dependence between isotope ratios and concentrations (Fig. 3) for the concentration range with measurable carbon isotope ratios. However, since some of the samples collected were too low in the concentration of the target compounds to be analyzed for carbon isotope ratios, it cannot be determined if the lower end of the observed distributions is 
biased due to limitations of the $\delta^{13} \mathrm{C}$ measurements or represents the true lower limit of the isotope ratios of atmospheric nitrophenols.

In spite of the various uncertainties in the comparison between the predicted and observed lower end of frequency distributions for the isotope ratios, the observations are consistent with the laboratory studies of Irei et al. (2015) which show that the formation of methyl nitrophenols by photooxidation of toluene in the atmosphere results in a carbon isotope fractionation between precursor and reaction product that is slightly larger than the KIE for the reaction of aromatic VOCs with the $\mathrm{OH}$ radical.

\subsection{Comparison of gas phase and PM phase isotope ratios}

Perraud et al. (2011) have suggested that there is a nonequilibrium in the partitioning of SVOCs between the particle phase and the gas phase and that, contrary to widely used equilibrium models, SVOCs, such as organic nitrates, can adsorb onto existing particles and, before partitioning back into the gas phase, are buried irreversibly into the particle. While fractionation due to the partitioning between different phases is usually small (Kaye, 1992) and within the uncertainty of the measurement, changes in carbon isotope ratio of SVOCs in the atmosphere will result in a difference in carbon isotope ratio between the two phases if partitioning into the particle phase is irreversible. Formation of nitrophenols from aromatic VOCs is the result of a gas phase reaction sequence and the only known reactions of nitrophenols are in the gas phase with the $\mathrm{OH}$ radical (Grosjean, 1991; Bejan et al., 2007) and no solid or aqueous phase loss processes are known, apart from possible oligomerization. Consequently, irreversible partitioning into particles should result in differences in carbon isotope ratios between the gas phase and particle phase for nitrophenols.

For the measurements presented here, the average concentration of nitrophenols in PM is only about $20 \%$ of the average of the total atmospheric nitrophenol concentrations, similar to the findings reported by Saccon et al. (2013). Consequently, on average, the carbon isotope ratio of total atmospheric nitrophenols is dominated by the carbon isotope ratio of gas phase nitrophenols. The frequency distributions (Fig. 4) as well as a comparison of average carbon isotope ratios (Fig. 5) show no systematic difference in the isotope ratios between the two phases. In the case of 4-nitrophenol, 3-methyl-4-nitrophenol and 2-methyl-4-nitrophenol, the differences between averages for PM + gas phase and PM only are less than $0.5 \%$; for 4-methyl-2-nitrophenol and 2,6dimethyl-4-nitrophenol the differences are less than $1 \%$. These differences are all within the uncertainties of the averages. The larger errors for 4-methyl-2-nitrophenol and 2,6dimethyl-4-nitrophenol are due to the smaller number of samples, which is less than 15 for each phase.

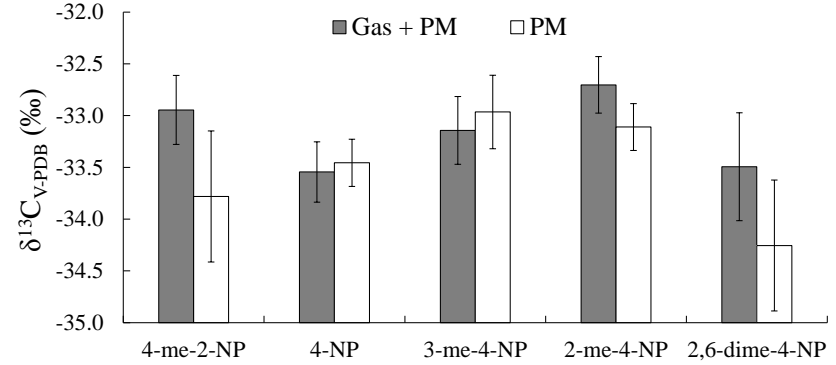

Figure 5. Comparison of average isotope ratios of nitrophenols found in PM alone and in the gas phase + PM. The error bars represent the error of the mean.

The distributions, as well as the average values, are based on a set of samples which only contained a limited subset of simultaneous measurements of the isotope ratios of total nitrophenols and particle phase nitrophenols. Therefore, the finding of very small differences in carbon isotope ratios between nitrophenols in PM and total nitrophenols only rules out a significant systematic enrichment in one of the two phases but not the existence of a disequilibrium for different atmospheric conditions. More insight into a possible disequilibrium between the two phases can be gained from the small subset of simultaneously collected PM and PM + gas phase samples.

For 2-methyl-4-nitrophenol, the most abundant targeted product from toluene photooxidation, there were eight pairs of samples in which the isotope ratios were quantified in both types of samples; 4-nitrophenol and 3-methyl-4-nitrophenol had six and two sample pairs, respectively. An overview of the differences between total and PM only isotope ratios for samples collected in parallel $\left(\Delta \delta^{13} \mathrm{C}\right)$ is shown in Fig. 6. On average the difference is $0.3 \%$ with an error of the mean of $0.5 \%$, consistent with the results in Fig. 5. However, the standard deviation for $\Delta \delta^{13} \mathrm{C}$ is $1.8 \%$, outside of the $99 \%$ confidence limit expected from the uncertainty of the measurements. Disequilibrium without significant systematic bias in $\Delta \delta^{13} \mathrm{C}$ indicates that exchange between the two phases is slower than the change of $\delta^{13} \mathrm{C}$ in one of the two phases. Since, apart from exchange with the gas phase, no processes are known that will change the concentration or carbon isotope ratio of nitrophenols in the particle phase, it is likely that the change of $\delta^{13} \mathrm{C}$ in the gas phase due to formation from aromatic VOCs or gas phase loss reactions of nitrophenols is creating the disequilibrium in carbon isotope ratio between the two phases. 
Table 4. Overview of the difference in delta values for sample pairs $\left(\Delta \delta^{13} \mathrm{C}\right)$ and environmental conditions for the summer and late fall measurements shown in Fig. 4.

\begin{tabular}{rrrrrr}
\hline & $\Delta \delta^{13} \mathrm{C}(\% \circ)^{\mathrm{a}}$ & $\begin{array}{r}\text { Temperature } \\
(\mathrm{K})\end{array}$ & $\begin{array}{r}{\left[\mathrm{O}_{3}\right]} \\
\left(\mathrm{nmol} \mathrm{mol}^{-1}\right)\end{array}$ & $\begin{array}{r}{\left[\mathrm{NO}_{2}\right]} \\
\left(\mathrm{nmol} \mathrm{mol}^{-1}\right)\end{array}$ & $\begin{array}{r}{\left[\mathrm{PM}_{2.5}\right]^{\mathrm{b}}} \\
\left(\mu \mathrm{g} \mathrm{m}^{-3}\right)\end{array}$ \\
\hline Late fall & $0.3 \pm 0.9(11)$ & 275 & 13 & 23 & 11 \\
Summer & $0.3 \pm 3.2(5)$ & 298 & 44 & 10 & 17 \\
\hline
\end{tabular}

a Average and standard deviation; number of data points is given in parenthesis. ${ }^{\mathrm{b}}$ Particulate matter $<2.5 \mu \mathrm{m}$

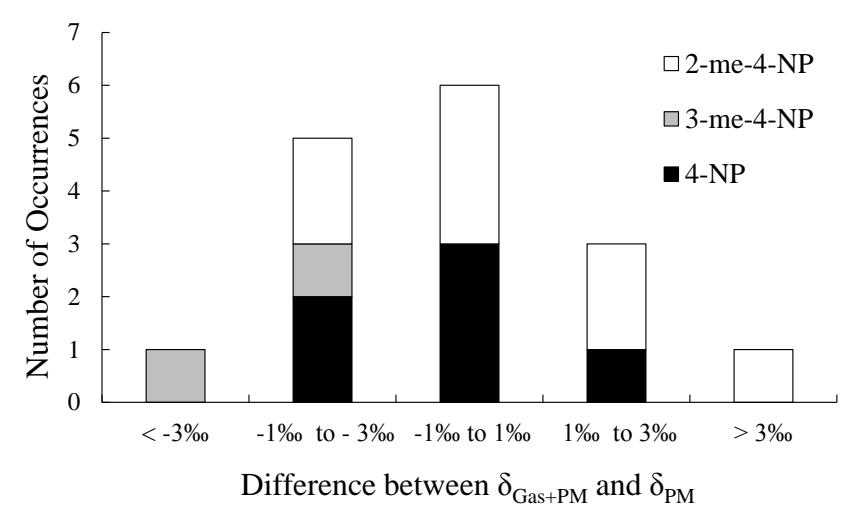

Figure 6. Frequency distribution for the difference in the stable carbon isotope ratio of target nitrophenols in the gas phase $+\mathrm{PM}$ and in PM for samples collected in parallel.

Indeed, the variability of $\Delta \delta^{13} \mathrm{C}$ for sample pairs collected in summer is substantially higher than for late fall, when photochemical activity is expected to be lower than in the summer (Table 4). Although the number of measurements is small and the averages are identical, the standard deviation of $\Delta \delta^{13} \mathrm{C}$ for summer sample pairs is $3.2 \%$ and well outside of the variability expected from measurement errors. In contrast to this the standard deviation of $\Delta \delta^{13} \mathrm{C}$ for late fall is only $0.9 \%$, which is only slightly higher than expected from the uncertainty of the measurements. The variances for the summer and winter data sets are statistically different with a $99.5 \%$ probability ( $F$ test).

In addition to a slower photochemical production or destruction of the nitrophenols in late fall, a lower variance of $\Delta \delta^{13} \mathrm{C}$ in late fall can also be caused by the temperature dependence of phase partitioning. For the sample pairs collected in summer, PM contributed on average $12 \%$ of the total atmospheric nitrophenol concentration. Therefore, the measured $\Delta \delta^{13} \mathrm{C}$ values are a good approximation for the difference in $\delta^{13} \mathrm{C}$ between nitrophenols in the gas phase and in PM. For the sample pairs collected in late fall, the contributions from PM range from $30 \%$ to approximately $100 \%$ and consequently the difference in $\delta^{13} \mathrm{C}$ between nitrophenols in the gas phase and in PM will be larger than the measured $\Delta \delta^{13} \mathrm{C}$ values. Unfortunately, for the late fall samples, the large contribution of measurement error to the $\Delta \delta^{13} \mathrm{C}$ val- ues, combined with the uncertainty of concentration measurements, prevents a meaningful determination of the difference in $\delta^{13} \mathrm{C}$ between nitrophenols in the gas phase and in PM.

\subsection{Correlation between isotope ratios of nitrophenols}

The three methyl nitrophenol isomers we studied are formed from the same precursor following the same initial reaction step, which is the addition of an $\mathrm{OH}$ radical to the aromatic ring of toluene. Consequently, it is expected that the freshly formed isomers will have similar carbon isotope ratios. Later differentiation in $\delta^{13} \mathrm{C}$ could result from differences in carbon isotope effects for the reaction sequences following the initial reaction. Similarly, different KIEs for the loss reactions of the different isomers could cause differences in $\delta^{13} \mathrm{C}$ between isomers.

Indeed, the average $\delta^{13} \mathrm{C}$ values of the three isomers are very similar (Table 2) and differ from each other only by $0.1 \%$ or less. However, based on the average, differences between isomers in individual samples cannot be ruled out. Figure 7 shows a plot of the carbon isotope ratios of 4-methyl2-nitrophenol and 3-methyl-4-nitrophenol vs. the carbon isotope ratio of 2-methyl-4-nitrophenol for all samples which could be analyzed for the carbon isotope ratio of more than one of the methyl nitrophenols. The data show scatter around the $1: 1$ line, but most of this scatter can be explained by measurement uncertainty. For approximately $50 \%$ of the data pairs, the difference in isotope ratios between isomers $\left(\Delta \delta^{13} \mathrm{C}\right)$ is within the uncertainty of the measurements, and only for 6 of the 58 data pairs is the difference larger than 3 times the measurement error. The mean value for $\Delta \delta^{13} \mathrm{C}$ is $0.15 \%$, which is less than the error of the mean $(0.18 \%$ o). The standard deviation for $\Delta \delta^{13} \mathrm{C}$ is $1.3 \%$, which is $0.6 \%$ o larger than expected from measurement errors alone. Although these findings cannot completely rule out the existence of differences in KIEs or rate constants for formation or removal processes between methyl nitrophenols, the impact of such differences can only be small and a systematic bias cannot be identified within the uncertainty of the measurements.

The standard deviations observed for differences between carbon isotope ratios of nitrophenols which are not isomers are substantially larger than expected from measurement un- 


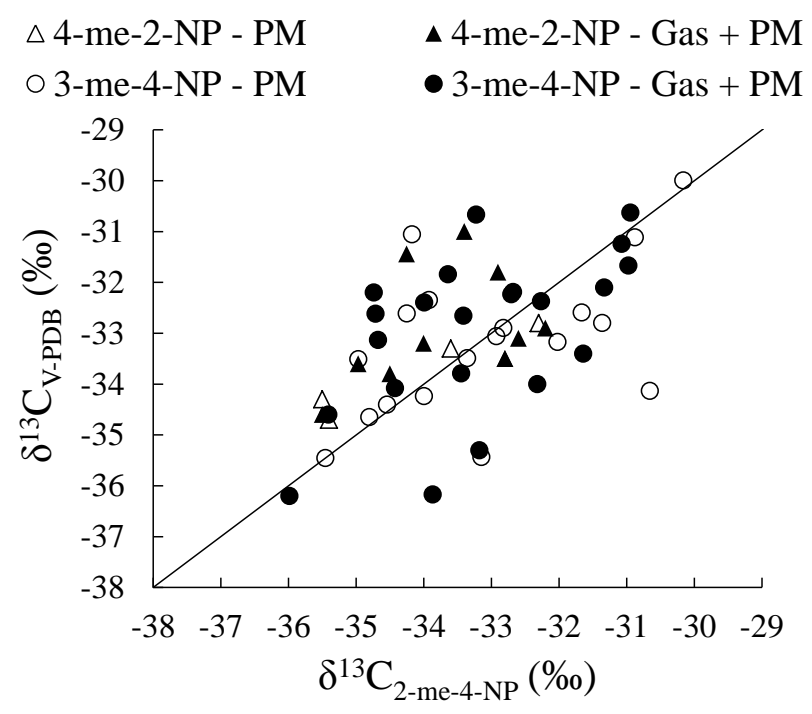

Figure 7. Plot of isotope ratios for 4-methyl-2-nitrophenol and 3methyl-4-nitrophenol ( $y$ axis) against 2-methyl-4-nitrophenol isotope ratios for filter samples.

certainty and very similar to the standard deviation expected from the variance of $\delta^{13} \mathrm{C}$ within the data sets for the individual nitrophenols (Table 5). However, on average the difference in isotope ratios $\left(\Delta \delta^{13} \mathrm{C}\right)$ between non-isomeric nitrophenols is only marginally larger than $\Delta \delta^{13} \mathrm{C}$ for the methyl nitrophenol isomers (Tables 2 and 5). To some extent this can be explained by the very similar carbon isotope ratios of the different precursor VOCs (Table 3). However, from the differences in KIEs for the initial step of the reaction sequence leading to formation of nitrophenols it is expected that isotope ratios of non-isomeric nitrophenols formed from unprocessed emissions will differ by a few per mill (Table 3 ). Compared to these predicted differences, the values actually observed for the average of $\Delta \delta^{13} \mathrm{C}$ are surprisingly small. This may be due to the fact that with increasing extent of atmospheric processing the carbon isotope ratio of the precursor will increase and that this increase will depend on the KIE and the rate constant for the reaction of precursor. Depending on the extent of processing, this will, at least partly, compensate for the larger depletion in ${ }^{13} \mathrm{C}$ for reaction products formed from unprocessed emissions since the more reactive aromatic precursor VOCs have lower KIEs. On average the observed $\Delta \delta^{13} \mathrm{C}$ are very small, suggesting that precursor processing has been on average substantial, independent of the precursor reactivity.

\subsection{Seasonal variation of the concentrations and carbon isotope ratios of nitrophenols}

Table 6 shows a comparison of 2-methyl-4-nitrophenol and 4-nitrophenol concentrations and carbon isotope ratios for different temperature ranges. The separation into different temperature ranges is based on the average temperatures dur- ing sampling. Measurements with average temperatures below $10^{\circ} \mathrm{C}$ were made between mid-October and the end of January, measurements with average temperatures exceeding $20^{\circ} \mathrm{C}$ in June, July and August. Also included are air quality data from two OME monitoring stations in Toronto (Fig. 2). Remarkably, a distinct seasonal difference in isotope ratios is not observed. With the exception of the 4-nitrophenol isotope ratios in PM, the difference in average carbon isotope ratios between measurements made at low and high temperatures is less than $0.5 \%$. For the 4-nitrophenol isotope ratios in PM this difference is $0.9 \%$, but this difference is within the uncertainty of the average values.

This is in contrast to the expectation that, due to higher photochemical activity in summer, samples collected in summer should be subject to more processing and therefore be, compared to less processed samples, enriched in ${ }^{13} \mathrm{C}$. A more detailed look at the dependence between temperature, wind direction and carbon isotope ratio can provide a possible explanation for this unexpected finding. Figure 8 shows the frequency of observations of $\delta^{13} \mathrm{C}$ values for methyl nitrophenols and 4-nitrophenol binned into intervals of $2 \% o$ and separated by wind direction and average temperature during sampling. The selection of the wind directions, north and southwest, was based on the number of available measurements and the difference in nearby major sources of nitrophenol precursors. Only samples with a wind direction that was stable (with $45^{\circ}$ ) during sampling were used for this analysis. The total number of samples fitting this criterion was 64 out of a total of 102. Three major highways and their intersections are located within $15 \mathrm{~km}$ or less southwest of the sampling locations, whereas there is only one major highway directly north of York University (Fig. 2).

For medium $\left(10\right.$ to $\left.20^{\circ} \mathrm{C}\right)$ and low $\left(<10^{\circ} \mathrm{C}\right)$ temperatures, the number of methyl nitrophenol data points in each $\delta^{13} \mathrm{C}$ bin is identical, while for high average temperatures the number of observations peaks in the center bin $(-34$ to $-32 \%$ ). Therefore, the absence of a difference in the seasonal averages of the methyl nitrophenol carbon isotope ratio is not due to the absence of a seasonal impact on processing but rather due to the coincidence that 17 out of $29 \delta^{13} \mathrm{C}$ measurements in summer are close to the average of all observations.

Nevertheless, it is somewhat surprising that only 3 of the 15 observations in the -34 to $-32 \%$ o bin were at high average temperatures since this bin represents the largest extent of methyl nitrophenol precursor processing. The most likely reason is a more pronounced influence of local scale processing on the methyl nitrophenol concentration and therefore also its carbon isotope ratio in summer compared to fall and winter.

Although the lower number of data points available for 4-nitrophenol results in higher statistical uncertainty of the distribution, Fig. 8 shows some substantial differences between the carbon isotope ratios of methyl nitrophenols and 4-nitrophenol. For 4-nitrophenol only $13 \%$ of all data points are in the -34 to $-32 \%$ range and more than $50 \%$ of the 
Table 5. Overview of difference in carbon isotope ratios $\left(\Delta \delta^{13} \mathrm{C}\right)$ between different nitrophenols analyzed in the same sample.

\begin{tabular}{lrrrr}
\hline & $n^{\mathrm{a}}$ & $\Delta \delta^{13} \mathrm{C}(\% \circ)^{\mathrm{b}}$ & ${\text { Observed SD }(\% o)^{\mathrm{c}}}$ & Expected SD (\%o $^{\mathrm{d}}$ \\
\hline 4-NP \& me-NP & 101 & -0.34 & 1.8 & 2.2 \\
2,6-dime-4-NP \& 4-NP & 17 & -0.24 & 2.5 & 2.4 \\
2,6-dime-4-NP \& me-NPe & 42 & -0.26 & 2.0 & 2.5 \\
\hline
\end{tabular}

${ }^{a}$ Number of measurement pairs. ${ }^{b}$ Average. ${ }^{c}$ Standard deviation determined from measurements pairs. ${ }^{d}$ Standard deviation expected from variability of individual nitrophenols. ${ }^{\mathrm{e}}$ All three methyl nitrophenol isomers studied.

Table 6. Average of measured 2-methyl-4-nitrophenol concentrations and carbon isotope ratios for different daily average temperatures. For comparison, air quality data from two monitoring sites of OME are also shown.

\begin{tabular}{|c|c|c|}
\hline PM samples & $\begin{array}{r}<10^{\circ} \mathrm{C} \\
17^{\mathrm{a}}\end{array}$ & $\begin{array}{r}>20^{\circ} \mathrm{C} \\
10^{\mathrm{a}}\end{array}$ \\
\hline Average $\left[\mathrm{O}_{3}\right]\left(\mathrm{nmol} \mathrm{mol}^{-1}\right)^{\mathrm{b}}$ & $12(15)$ & $29(33)$ \\
\hline Average $\left[\mathrm{NO}_{2}\right]\left(\mathrm{nmol} \mathrm{mol}^{-1}\right)^{\mathrm{b}}$ & $23(18)$ & $17(15)$ \\
\hline Average $\left[\mathrm{PM}_{2.5}\right]\left(\mu \mathrm{g} \mathrm{m}^{-3}\right)^{\mathrm{b}}$ & $6(6)$ & $12(13)$ \\
\hline Average $\left[\mathrm{SO}_{2}\right]\left(\mu \mathrm{mol} \mathrm{mol}^{-1}\right)^{\mathrm{b}}$ & 1.4 & 1.0 \\
\hline Average $[\mathrm{CO}]\left(\mu \mathrm{mol} \mathrm{mol}^{-1}\right)^{\mathrm{b}}$ & 0.18 & 0.21 \\
\hline$\delta^{13} \mathrm{C}_{2-\mathrm{me}-4-\mathrm{NP}}(\% \circ)^{\mathrm{c}}$ & $-32.1 \pm 0.4$ & $-32.5 \pm 0.3$ \\
\hline [2-me-4-NP] $\left(\mathrm{ng} \mathrm{m}^{-3}\right)^{\mathrm{c}}$ & $1.3 \pm 0.6$ & $0.2 \pm 0.1$ \\
\hline$\delta^{13} \mathrm{C}_{4-\mathrm{NP}}(\% o)^{\mathrm{d}}$ & $-33.7 \pm 0.5$ & $-32.8 \pm 0.8$ \\
\hline$[4-N P]\left(\operatorname{ng~m}^{-3}\right)^{d}$ & $2.5 \pm 1.2$ & $0.7 \pm 0.3$ \\
\hline Gas + PM samples & $10^{\mathrm{a}}$ & $10^{\mathrm{a}}$ \\
\hline Average $\left[\mathrm{O}_{3}\right]\left(\mathrm{nmol} \mathrm{mol}^{-1}\right)^{\mathrm{b}}$ & $9(12)$ & $34(39)$ \\
\hline Average $\left[\mathrm{NO}_{2}\right]\left(\mathrm{nmol} \mathrm{mol}^{-1}\right)^{b}$ & $25(22)$ & $14(10)$ \\
\hline Average $\left[\mathrm{PM}_{2.5}\right]\left(\mu \mathrm{g} \mathrm{m}^{-3}\right)^{\mathrm{b}}$ & $8(9)$ & $12(13)$ \\
\hline Average $\left[\mathrm{SO}_{2}\right]\left(\mu \mathrm{mol} \mathrm{mol}^{-1}\right)^{\mathrm{b}}$ & 2.0 & 1.3 \\
\hline Average $[\mathrm{CO}]\left(\mu \mathrm{mol} \mathrm{mol}^{-1}\right)^{\mathrm{b}}$ & 0.21 & 0.21 \\
\hline$\delta^{13} \mathrm{C}_{2-\mathrm{me}-4-\mathrm{NP}}(\% \circ)^{\mathrm{c}}$ & $-32.3 \pm 0.5$ & $-32.8 \pm 0.5$ \\
\hline$[2-m e-4-N P]\left(\mathrm{ng} \mathrm{m}^{-3}\right)^{\mathrm{c}}$ & $3.6 \pm 0.9$ & $2.2 \pm 0.3$ \\
\hline$\delta^{13} \mathrm{C}_{4-\mathrm{NP}}(\% o)^{\mathrm{d}}$ & $-33.9 \pm 0.6$ & $-33.6 \pm 0.4$ \\
\hline$[4-N P]\left(\operatorname{ng~m}^{-3}\right)^{d}$ & $5.7 \pm 1.7$ & $8.9 \pm 2.3$ \\
\hline
\end{tabular}

a Number of measurements of 2-me-4-NP in each category. ${ }^{b}$ Pollution data acquired from the Ontario Ministry of the Environment historical pollutant data; Toronto West site and values are averaged over the sampling time. Data from the Toronto North site are listed in brackets, when available. ${ }^{c}$ Average \pm error of the mean. ${ }^{\mathrm{d}}$ 4-NP data were not available for all samples with 2-me-4-NP measurements; the 4-NP averages are based on a total of 17 PM and 18 gas + PM samples.

$\delta^{13} \mathrm{C}$ values measured at high average temperatures are below $-34 \%$. This can be explained by the different reactivity of the precursors. The rate constant for the reaction of benzene with the $\mathrm{OH}$ radical is only one-fourth of that for the reaction of toluene (Table 3) and therefore photochemical processing results in lower enrichment of ${ }^{13} \mathrm{C}$ in the products from reactions of benzene compared to products derived from toluene.

The preference of low and medium enrichment of nitrophenols in ${ }^{13} \mathrm{C}$ during summer is independent of wind direc-
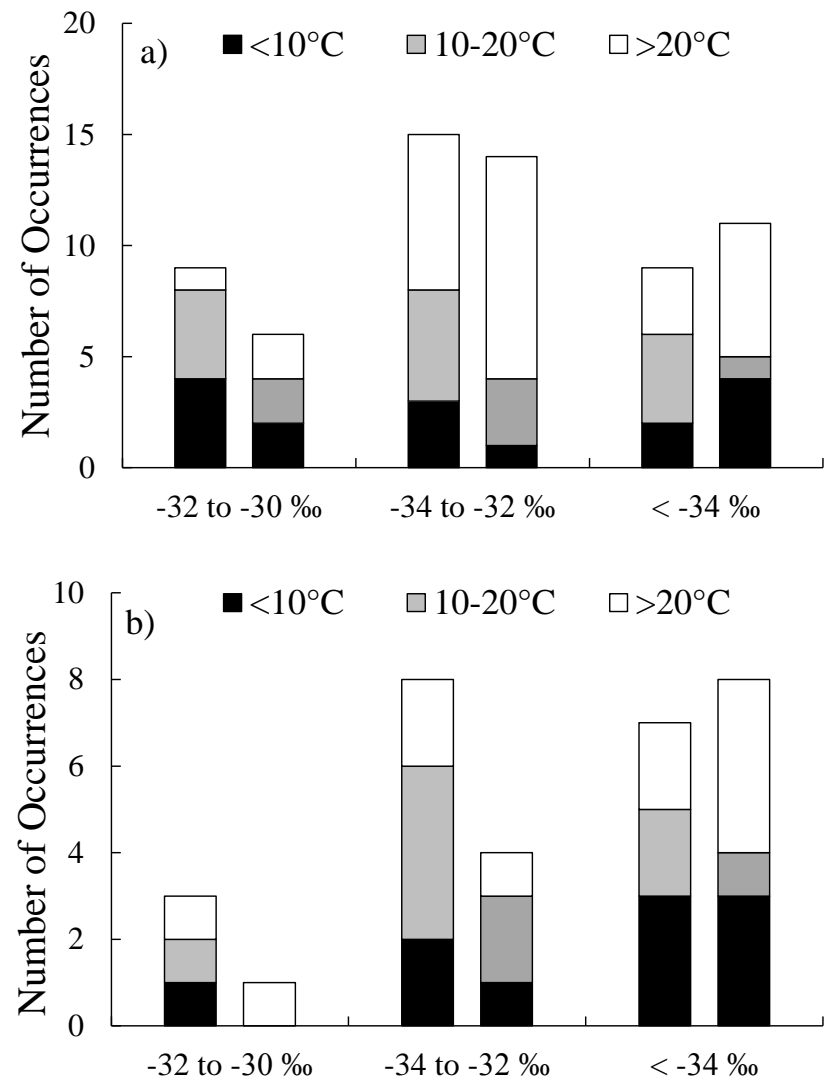

Figure 8. Gas + PM samples for the three methyl nitrophenols (a) and 4-nitrophenol (b) were binned according to isotope ratio and separated by the given temperature ranges. The left column in each bin has winds originating from the north and the right column in each bin has winds originating from the southwest. Wind direction was based on HYSPLIT (Hybrid Single Particle Lagrangian Integrated Trajectory Model by Air Resources Laboratory, NOAA) trajectory analysis.

tion. Compared to northerly wind directions, the larger number of observations under southwesterly airflow reflects the larger percentage of observations with southwesterly wind in summer (18 of 29) and not a wind direction dependence of methyl nitrophenol carbon isotope ratios. Since it is expected that the different wind directions result in different pollution levels, this is consistent with the finding that there is no systematic dependence between the concentration of 
methyl nitrophenols and carbon isotope ratio (Fig. 2). Similarly, the carbon isotope ratios of the methyl nitrophenols and 4-nitrophenol show no correlation with $\mathrm{CO}, \mathrm{NO}_{2}, \mathrm{O}_{3}$ or oxidant $\left(\mathrm{O}_{3}+\mathrm{NO}_{2}\right)$ concentrations $\left(R^{2}\right.$ is consistently below $0.1)$.

Although the nitrophenols exhibit only small seasonal changes in carbon isotope ratios, there are substantial differences in concentrations. For 2-methyl-4-nitrophenol and 4nitrophenol the difference in concentrations in PM between summer and winter is a factor of 6.5 and 3.5, respectively. Most of these differences can be explained by a temperature dependence of the distribution between gas phase and PM. For average temperatures exceeding $20^{\circ} \mathrm{C}$, slightly less than $10 \%$ of the total concentration is found in PM. For average temperatures below $10^{\circ} \mathrm{C}$ the fraction in $\mathrm{PM}$ increases to an average of approximately $40 \%$.

There are some differences in $\mathrm{PM}+$ gas concentrations between the two different temperature ranges. The average 2-methyl-4-nitrophenol concentration in PM + gas is at low temperatures on average approximately $60 \%$ higher than at high temperatures. An increase in photochemical processing of the precursors can be ruled out as explanation for the higher methyl nitrophenol concentrations at low temperatures. It is unlikely that photochemical processing is faster in winter and fall than in summer and the methyl nitrophenol isotope ratios show, on average, no indication for enhanced processing at low temperatures. The most likely explanation is higher precursor concentrations in fall and winter. The concentration of 2-methyl-4-nitrophenol in $\mathrm{PM}+$ gas is correlated $\left(R^{2}=0.64\right)$ with the $\mathrm{NO}_{2}$ concentration (Fig. 9a). Therefore it is expected that on average, higher $\mathrm{NO}_{2}$ concentrations in fall and winter will result in higher 2-methyl4-nitrophenol levels. The larger $\mathrm{NO}_{2}$ concentrations in fall and winter may be attributed to the decreased boundary layer height coupled with increased pollution rates, but the higher photolysis rate of $\mathrm{NO}_{2}$ in summer may also contribute to the difference in $\mathrm{NO}_{2}$ concentrations between seasons.

Both toluene and $\mathrm{NO}_{2}$ are required for the formation of methyl nitrophenols in the atmosphere and it is expected that the concentration of toluene also will influence the formation rate of methyl nitrophenols. However, there is a weak correlation of the $\mathrm{NO}_{2}$ concentration with other indicators of atmospheric pollution such as $\mathrm{CO}\left(R^{2}=0.33\right)$ and $\mathrm{SO}_{2}$ $\left(R^{2}=0.41\right)$, which prevents separating between the influence of $\mathrm{NO}_{2}$ and other precursors and it is therefore not possible to distinguish between the impact of different pollutants on methyl nitrophenol concentrations.

In contrast to 2-methyl-4-nitrophenol, the correlation between the concentrations of 4-nitrophenol and $\mathrm{NO}_{2}$ is only weak (Fig. 9b). This indicates that, consistent with the low reactivity of 4-nitrophenol and its benzene precursor, the processes determining the concentration of 4-nitrophenol are occurring at a timescale that is different from the processes determining the $\mathrm{NO}_{2}$ concentrations.
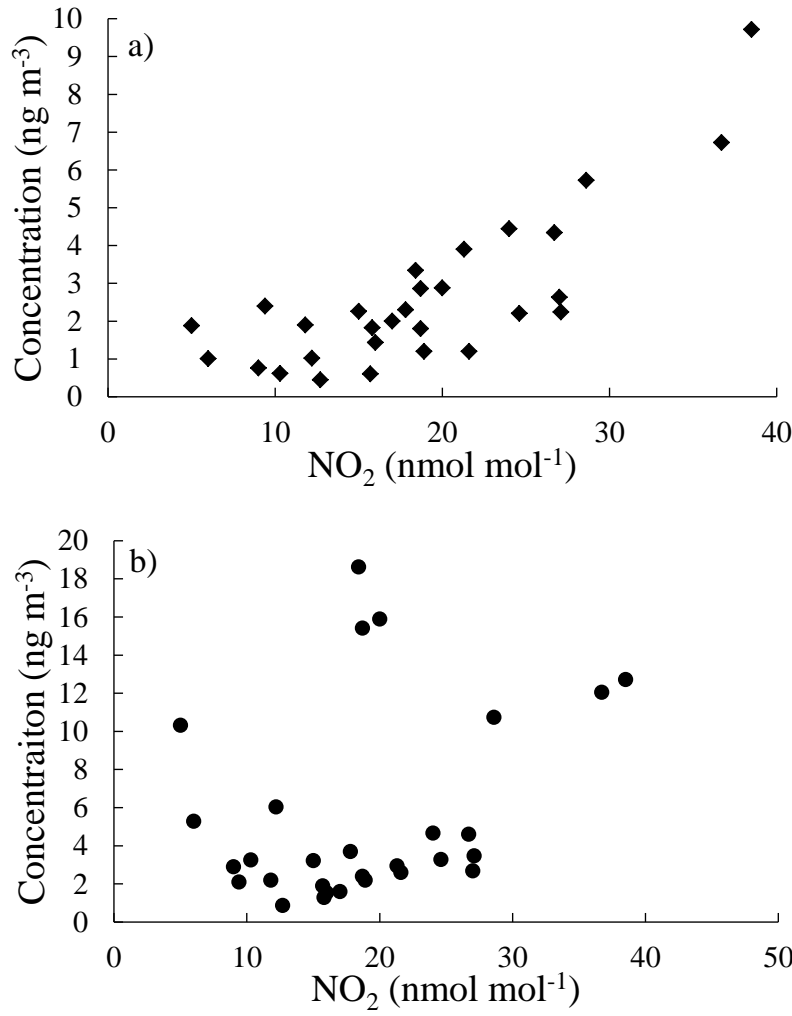

Figure 9. Plot of gas + PM sample concentrations of 2-methyl-4nitrophenol (a) and 4-nitrophenol (b) vs. $\mathrm{NO}_{2}$ mixing ratios, which are hourly data averaged over the sampling time for each filter sample from the Ontario Ministry of the Environment historical pollutant data, Toronto West site.

Atmospheric nitrophenols are produced by photochemical oxidation of aromatic VOCs in the presence of $\mathrm{NO}_{x}$. Since atmospheric oxidants $\left(\mathrm{O}_{3}\right.$ and $\left.\mathrm{NO}_{2}\right)$ are also formed from photooxidation of VOCs, we expect correlation between oxidant and nitrophenol concentrations. Indeed, there is a strong correlation $\left(R^{2}=0.60\right)$ between the concentration of oxidants and 4-nitrophenol (Fig. 10a). Surprisingly, the correlation between 2-methyl-4-nitrophenol and oxidant concentrations is only weak (Fig. 10b). This most likely reflects the different reactivity of the precursors (Table 3 ) and indicates that the timescale for processes determining oxidant levels is similar to the timescale determining formation of 4-nitrophenol, but different from that for 2-methyl-4-nitrophenol formation.

\section{Conclusions}

In this study, concentration and stable carbon isotope ratio measurements of nitrophenols in Toronto were taken. On average, the ${ }^{13} \mathrm{C}$ depletion relative to the carbon isotope ratios of the precursors is approximately $6 \%$, and the observed $\delta^{13} \mathrm{C}$ values range from -37 to $-28 \%$. The substantial variability of the nitrophenol carbon isotope ratios can be ex- 

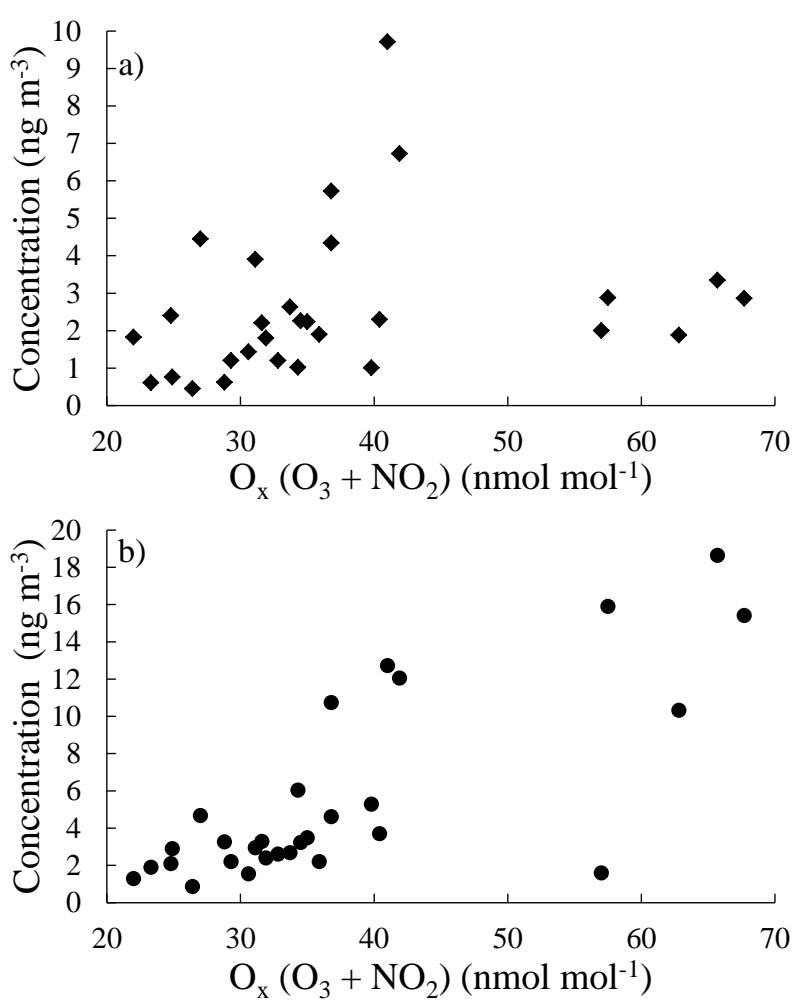

Figure 10. Plot of gas + PM sample concentrations of 2-methyl-4nitrophenol (a) and 4-nitrophenol (b) vs. oxidant $\left(\mathrm{O}_{3}+\mathrm{NO}_{2}\right)$ mixing ratios, which are hourly data averaged over the sampling time for each filter sample from the Ontario Ministry of the Environment historical pollutant data, Toronto West site.

plained by a varying degree of photochemical processing. Consequently, changes in the carbon isotope ratio of atmospheric nitrophenols are indicators for differences in photochemical processing, although currently no simple quantitative relation between nitrophenol isotope ratio and photochemical age has been established. The combination of carbon isotope ratio and concentration measurements provides strong evidence that, for the conditions studied here, secondary processes in the atmosphere are the dominant source for the target compounds.

The lower end of measured ambient isotope ratios is about 2 to $3 \%$ lower than predictions based on the KIE for the reaction of the precursor with $\mathrm{OH}$ radicals. This is consistent with results of the laboratory studies of Irei et al. (2015) and therefore provides additional evidence for a predominantly photochemical origin of the nitrophenols.

On average, the difference in carbon isotope ratios of nitrophenols between the gas phase and the particle phase is very small. This suggests that, on average, there is equilibrium between nitrophenols in the gas phase and in the particle phase, but there are several observations of a significant difference in nitrophenol carbon isotope ratios between gas and particle phase. Since this is only observed in summer, it can be concluded that in these cases photochemical production or removal of nitrophenols is faster than their exchange between the two phases. The assumption of significant local photochemical processing of nitrophenols in summer is also supported by the difference between summer and winter carbon isotope frequency distributions of methyl nitrophenols.

There is no significant correlation between the carbon isotope ratio of nitrophenols and their concentration. This demonstrates that, for the conditions studied here, atmospheric mixing is the dominant process in determining the concentrations of nitrophenols. Indeed, for some nitrophenols strong correlations between their concentrations and the concentration of precursors or indicators of pollution are found. In principle in aged air masses with no impact from nearby sources nitrophenol carbon isotope ratios substantially heavier than the carbon isotope ratios of the precursors can be expected, which was not observed. It cannot be excluded that the lack of observations of such low nitrophenol isotope ratios is due to the limited ability to measure carbon isotope ratios in samples with very low nitrophenol concentrations. However, the percentage of samples for which none of the nitrophenols could be analyzed for carbon isotope ratios is small and it can therefore be concluded that for the conditions studied here such conditions will be the exception.

The concentration of 4-nitrophenol is strongly correlated with the oxidant $\left(\mathrm{O}_{3}+\mathrm{NO}_{2}\right)$ levels whereas there is no significant correlation between the concentration of other nitrophenols and oxidant concentration. It can be concluded that the processes determining oxidant concentrations are occurring on timescales that are better represented by the processes resulting in formation of 4-nitrophenols than those for formation of alkyl nitrophenols. Most likely these differences in timescales are determined by the reactivity of the aromatic precursors of the different nitrophenols.

The importance of precursor reactivity on the carbon isotope ratios of nitrophenols is supported by the comparison of carbon isotope ratios of different methyl nitrophenol isomers. Overall, these differences in carbon isotope ratios for different isomers are small compared to the overall variability of the carbon isotope ratios of individual isomers of methyl nitrophenols.

Combining measurement of the atmospheric concentrations of secondary organic compounds with measurement of their carbon isotope ratios provides detailed insight into the processes and the timescales at which the formation occurs. However, currently this insight is limited to qualitative or semi-quantitative conclusions since the current quantitative understanding of the dependence between the carbon isotope ratio of secondary organic compounds and photochemical aging is limited. Another current limitation of the use of isotope ratios is resulting from the required minimum concentrations for meaningful isotope ratio measurements, which limits the possibility to study the relationship between 
isotope ratio and concentration under conditions of very low processing or at very low pollutant levels.

Acknowledgements. The authors would like to acknowledge Darrell Ernst and Wendy Zhang at Environment Canada for technical support in isotope ratio measurements. This research was supported financially by the Natural Sciences and Engineering Research Council of Canada (NSERC) and the Canadian Foundation for Climate and Atmospheric Sciences (CFCAS).

Edited by: E. Harris

\section{References}

Anderson, R. S., Iannone, R., Thompson, A. E., Rudolph, J., and Huang, L.: Carbon kinetic isotope effects in the gas-phase reactions of aromatic hydrocarbons with the $\mathrm{OH}$ radical at $296 \pm 4 \mathrm{~K}$, Geophys. Res. Lett., 31, L15108, doi:10.1029/2004GL020089, 2004.

Atkinson, R.: Atmospheric chemistry of VOCs and $\mathrm{NO}_{x}$, Atmos. Environ., 34, 2063-2101, 2000.

Atkinson, R., Aschmann, S. M., and Arey, J.: Reactions of $\mathrm{OH}$ and $\mathrm{NO}_{3}$ radicals with phenol, cresols, and 2-nitrophenol at $296 \pm 2$ K, Environ. Sci. Technol., 26, 1397-1403, 1992.

Bejan, I., Barnes, I., Olariu, R., Zhou, S., Wiesen, P., and Benter, T.: Investigations on the gas-phase photolysis and $\mathrm{OH}$ radical kinetics of methyl-2-nitrophenols, Phys. Chem. Chem. Phys., 9, 5686-5692, 2007.

Bolzacchini, E., Bruschi, M., Hjorth, J., Meinardi, S., Orlandi, M., Rindone, B., and Rosenbohm, E.: Gas-phase reaction of phenol with $\mathrm{NO}_{3}$, Environ. Sci. Technol., 35, 1791-1797, 2001.

Calvert, J. G., Atkinson, R., Becker, K. H., Kamens, R. M., Seinfeld, J. H., Wallington, T. J., and Yarwood, G.: The mechanisms of atmospheric oxidation of aromatic hydrocarbons, Oxford University Press, New York, USA, 2002.

Craig, H.: Isotopic standards for carbon and oxygen and correction factors for mass-spectrometric analysis of carbon dioxide, Geochem. Cosmochim. Ac., 12, 133-149, 1957.

Forstner, H., Flagan, R., and Seinfeld, J.: Secondary organic aerosol from the photooxidation of aromatic hydrocarbons: Molecular composition, Environ. Sci. Technol., 31, 1345-1358, 1997.

Gensch, I., Kiendler-Scharr, A., and Rudolph, J.: Isotope ratio studies of atmospheric organic compounds: principles, methods, applications and potential, Int. J. Mass Spectrom., 365-366, 206221, 2014.

Glaser, K., Vogt, U., and Baumbach, G.: Vertical profiles of $\mathrm{O}_{3}$, $\mathrm{NO}_{2}, \mathrm{NO}_{x}, \mathrm{VOC}$, and meteorological parameters during the Berlin Ozone Experiment (BERLIOZ) campaign, J. Geophys. Res., 108, 8253, doi:10.1029/2002JD002475, 2003.

Goldstein, A. and Shaw, S.: Isotopes of volatile organic compounds: An emerging approach for studying atmospheric budgets and chemistry, Chem. Rev., 103, 5025-5048, 2003.

Google Earth Pro: Version 7.1.2.2041, August 23, 2009, $43^{\circ} 46^{\prime} 25.13^{\prime \prime} \mathrm{N}, 79^{\circ} 30^{\prime} 22.00^{\prime \prime} \mathrm{W}$, elevation $0 \mathrm{~m}$, eye altitude $17.86 \mathrm{~km}$, Toronto, Canada, Map Data: Google, Digital Globe, First Base Solutions, NOAA, 2015.

Grosjean, D.: Atmospheric fate of toxic aromatic compounds, Sci. Total Environ., 100, 367-414, 1991.
Hamilton, J., Webb, P., Lewis, A., and Reviejo, M.: Quantifying small molecules in secondary organic aerosol formed during the photo-oxidation of toluene with hydroxyl radicals, Atmos. Environ., 39, 7263-7275, 2005.

Harrison, M. A. J., Heal, M. R., and Cape, J. N.: Evaluation of the pathways of tropospheric nitrophenol formation from benzene and phenol using a multiphase model, Atmos. Chem. Phys., 5, 1679-1695, doi:10.5194/acp-5-1679-2005, 2005.

Herrmann, H., Exner, M., Jacobi, H.-W., Raabe, G., Reese, A., and Zellner, R.: Laboratory studies of atmospheric aqueous-phase free-radical chemistry: Kinetic and spectroscopic studies of reactions of $\mathrm{NO}_{3}$ and $\mathrm{SO}_{4}^{-}$radicals with aromatic compounds, Faraday Discuss., 100, 129-153, 1995.

Inomata, S., Tanimoto, H., Fujitani, Y., Sekimoto, K., Sato, K., Fushimi, A., Yamada, H., Hori, S., Kumazawa, Y., Shimono, A., and Hikida, T.: On-line measurements of gaseous nitro-organic compounds in diesel vehicle exhaust by proton-transfer-reaction mass spectrometry, Atmos. Environ., 73, 195-203, 2013.

Inomata, S., Fushimi, A., Sato, K., Fujitani, Y., and Yamada, H.: 4-nitrophenol, 1-nitropyrene, and 9-nitroanthracene emissions in exhaust particles from diesel vehicles with different exhaust gas treatments, Atmos. Environ., 110, 93-102, 2015.

International Satellite Cloud Climatology Project: http://isccp.giss. nasa.gov/, last access: 22 July 2015.

Irei, S., Rudolph, J., and Huang, L: Compound-specific stable carbon isotope ratios of phenols and nitrophenols derivatized with N,O-bis(trimethylilyl)trifluoroacetamide, Anal. Chim. Acta, 786, 95-102, 2013.

Irei, S., Rudolph, J., Huang, L., Auld, J., Collin, F., and Hastie, D.: Laboratory studies of carbon kinetic isotope effects on the production mechanism of particulate phenolic compounds formed by toluene photooxidation: a tool to constrain reaction pathways, J. Phys. Chem, 119, 5-13, 2015.

Jang, M. and Kamens, R.: Characterization of secondary aerosol from the photooxidation of toluene in the presence of $\mathrm{NO}_{x}$ and 1-Propene, Environ. Sci. Technol., 35, 3626-3639, 2001.

Kaye, J. A.: Isotope effects in gas-phase chemical reactions and photodissociation processes: Overview, in: Isotope effects in gasphase chemistry, edited by: Kaye, J. A., American Chemical Society, USA, 1-14, 1992.

Moukhtar, S., Saccon, M., Kornilova, A., Irei, S., Huang, L., and Rudolph, J.: Method for determination of stable carbon isotope ratio of methylnitrophenols in atmospheric particulate matter, Atmos. Meas. Tech., 4, 2453-2464, doi:10.5194/amt-4-2453-2011, 2011.

Perraud, V., Bruns, E. A., Ezell, M. J., Johnson, S. N., Yu, Y., Alexander, M. L., Zelenyuk, A., Imre, D., Chang, W. L., Dabdub, D., Pankow, J. F., and Finlayson-Pitts, B. J.: Nonequilibrium atmospheric secondary organic aerosol formation and growth, $\mathrm{P}$. Natl. Acad. Sci. USA., 109, 2836-2841, 2011.

Rudolph, J: Gas chromatography-isotope ratio mass spectrometry, in: Volatile organic compounds in the atmosphere, edited by: Koppmann, R., Blackwell Publishing Ltd., UK, 388-466, 2007.

Rudolph, J., Czuba, E., Norman, A. L., Huang, L., and Ernst, D.: Stable carbon isotope composition of nonmethane hydrocarbons in emissions from transportation related sources and atmospheric observations in an urban atmosphere, Atmos. Environ., 36, 1173$1181,2002$. 
Saccon, M., Busca, R., Facca, C., Huang, L., Irei, S., Kornilova, A., Lane, D., and Rudolph, J.: Method for the determination of concentration and stable carbon isotope ratios of atmospheric phenols, Atmos. Meas. Tech., 6, 2965-2974, doi:10.5194/amt6-2965-2013, 2013.

Sato, K., Hatakeyama, S., and Imamura, T.: Secondary organic aerosol formation during the photooxidation of toluene: $\mathrm{NO}_{x}$ dependence of chemical composition, J. Phys. Chem. A, 111, 9796-9808, 2007.
Tremp, J., Mattrel, P., Fingler, S., and Giger, W.: Phenols and nitrophenols as tropospheric pollutants: Emissions from automobile exhausts and phase transfer in the atmosphere, Water Air Soil Poll., 68, 113-123, 1993. 